\title{
Homosexuality: Road to Visibility
}

\author{
Gautami Kapila $^{1 *}$, Dr Arun Kumar²
}

\section{ABSTRACT}

The term "Homosexuality" has always been the topic of great discussion. The purpose of choosing this topic is predominantly the unacceptance and widespread discrimination of homosexuals, in all aspects of the life. Earlier, homosexuality was considered "unnatural" or "dysfunctional", but research in this field has shown that homosexuality is an example of a normal and natural variation in human sexuality and is not in and of itself a source of negative psychological effects. This paper looks at the various issues concerning Homosexuality, it's origin and the possible explanation for such orientation. It will also look at the political approach and the various factors hampering their development as a human being.

Keywords: Homosexuality, Visibility

Sexual Orientation is a term used to portray our examples of enthusiastic, sentimental, and sexual fascination and our feeling of individual and social personality focused around those attractions. An individual's sexual introduction is not a dark or white matter; sexual introduction exists along a continuum, with select appreciation for the inverse sex toward one side of the continuum and restrictive fascination in the same sex on the other.

Heterosexuality (attraction the inverse sex), homosexuality ( attraction towards same sex), and bisexuality (attraction towards either sex) are the three most usually examined classifications of sexual introduction, however are in no way, shape or form the main classes in the realm of sexual recognizable proof names.

Few issues are as hotly challenged as what decides an individual's sexual introduction. While most researchers consider that nature and support both assume complex parts, the determinants of sexual introduction are still inadequately caught on. Flow research into its underpinnings much of the time concentrates on the part of, nature's domain, cerebrum structure, and hormones. Homosexuality (from Ancient Greek ónós, signifying "same", and Latin sexes, signifying "sex") is sentimental fascination, sexual fascination or sexual conduct between parts of the same sex or sex. As a sexual introduction, homosexuality seems to be "a continuing example of enthusiastic, sentimental, and/or sexual attractions" principally or solely to individuals of the same sex. It

\footnotetext{
${ }^{1}$ MA, Clinical Psychology, Amity Institute of Behavioural Health and Allied Sciences, Uttar Pradesh, Noida

${ }^{2}$ Associate Professor, Clinical Psychology, Amity Institute of Behavioural Health and Allied Sciences, Uttar Pradesh, Noida

*Corresponding Author

(C) 2015 I G Kapila, A Kumar; licensee IJIP. This is an Open Access Research distributed under the terms of the Creative Commons Attribution License (http://creativecommons.org/licenses/by/2.0), which permits unrestricted use, distribution, and reproduction in any Medium, provided the original work is properly cited.
} 


\section{Homosexuality: Road to Visibility}

"likewise alludes to an individual's feeling of character focused around those attractions, related practices, and participation in a group of other people who offer those attractions.

There is no agreement among researchers concerning why an individual creates a specific sexual introduction; however naturally based speculations for the reason for sexual introduction are supported by specialists, which indicate hereditary elements, the early the earth, or both in combo. There is no substantive proof which recommends child rearing or early youth encounters assume a part concerning sexual introduction; regarding same-sex sexual conduct, imparted or familial environment assumes no part for men and minor part for ladies. While some hold the view that gay person action is unnatural, despite the fact that exploration has demonstrated that homosexuality is a sample of an ordinary and characteristic variety in human sexuality and is not all by itself a wellspring of adverse mental impacts. The most well-known terms for gay person individuals are lesbian for females and gay for guys, however gay is additionally used to allude by and large to both gay person guys and females.. Gay person conduct has additionally been reported and is seen in a lot of people non-human creature species.

\section{Historical roots of Homosexuality}

The use of the term homosexuality in the study of ancient sexuality has found some dissatisfaction, due to the lack of a specific term in ancient literature corresponding to the modern concept of persons who are consistently sexually attracted to their own gender, versus the opposite sex.

-The largest amount of material pertinent to the history of homosexuality is from Greece, from notable philosophers and writers such as Plato, Xenophon, Plutarch, and pseudo-Lucian, to plays by Aristophanes, to Greek artwork and vases. James B. De Young notes that homosexuality seems to have existed more widely among the ancient Greeks more than among any other ancient culture. The main form of this was pederasty, a custom that seems to have been practiced mostly among the upper classes, in which an older man (the eras test) would make a young free boy (the erogenous) his sex partner, and become his mentor. This was regulated by the State as an institution. However, this practice was usually a supplement to marriage, and thus is seen as being done by bisexuals.

-After Greece, Rome is the next most significant entity in the history of homosexuality, and this cultural practice in both is understood by scholars as being what the apostle Paul is immediately referring to in condemning homosexuality in Romans 1 . Romans emperors were sometimes the most notorious examples of homosexuality. Edward Gibbon, in his History of the Decline and Fall of the Roman Empire, wrote that "of the first fifteen emperors Claudius was the only one whose taste in love was entirely correct (not homo-sexual].According to psychiatrist and sexual historian Norman Sussman, "In contrast to the self-conscious and elaborate efforts of the Greeks to glorify and idealize homosexuality, the Romans simply accepted it as a matter of fact and as an inevitable part of human sexual life. Pederasty was just another sexual activity. Many of the 


\section{Homosexuality: Road to Visibility}

most prominent men in Roman society were bisexual if not homosexual. Julius Caesar was called by his contemporaries every woman's man and every man's woman."

-In North America, the Spanish and French explorers and missionaries who visited the New World quickly became aware of widespread Indian transvestism (men dressing as women) and homosexuality. Writing in 1776, Father Charlevoix, a Jesuit priest, found the Iroquois to have "an excess of effeminacy and lewdness. There are men unashamed to their women's clothing and to practice all the occupations of women, from which follows corruption that I cannot express. They pretend that its usage comes from their religion. These effeminates never marry and abandon themselves to the most infamous passions. "Greenberg reports that there was widespread male homosexuality among the Mayans in Central America: “A strong homosexual component pervades close friendships of young married Mayan men as they'll as bachelors in southern Mexico and among Guatemalan Indians.”

-The Old Testament of the Bible mentions Egypt as one of the nation's exampling sins which Israel is to avoid, including homosexuality. (Lv. 18:3) While no legal texts are yet possessed, other stories testify of homosexual acts and attitudes. The earliest and longest version of the Contending's of Horus and Seth (Greek transliterations, or Heru and Set from Egyptian), dated c. 1160 B.C., late in the 20th Dynasty in the New Kingdom, with elements of religious mythology which are likely older, tells of Set, who is before manifested as heterosexual, perpetrating a homosexual act upon Horus. This is seen as shameful by Ruler Ennead. Seth is also said to have become pregnant by eating lettuce with the semen of Horus on it, placed there by his mother. An earlier version (est. 2,000 B.C.) is similar.

-The sexual revolution can be seen as an outgrowth of a process. Though its roots may be traced back as far as the Enlightenment (Rousseau, Marquis de Sade) and the Victorian era (Algernon Charles Swinburne's scandalous Poems and Ballads of 1866), it was a development in the modern world which saw the significant loss of pottery by the values of amorality rooted in the Christian tradition and the rise of permissive societies, of attitudes that are accepting of greater sexual freedom and experimentation that spread all over the world and are captured in the concept of "free love". The sexual revolution was initiated by those who shared a belief in the detrimental impact of sexual repression, a view that had previously been argued by Wilhelm Reich and D. H. Lawrence, by Sigmund Freud and by the Surrealist movement.. The sexual revolution of the sixties was an uprising rooted in a conviction that the erotic should be celebrated as a normal part of life and not repressed by family, industrialized sexual morality, religion and the state.

-Freud, among others, argued that neither predominantly different- nor same-sex sexuality were the norm, instead that what is called "bisexuality" is the normal human condition thwarted by society. A 1901 medical dictionary lists heterosexuality as "perverted" different-sex attraction, while by the 1960s its use in all forums referred to "normal" different-sex sexuality. In 1948 


\section{Homosexuality: Road to Visibility}

Alfred Kinsey publishes Sexual Behaviour in the Human Male, popularly known as the Kinsey Reports. Homosexuality was deemed to be a psychiatric disorder for many years, although the studies this theory was based on they're later determined to be flawed. In 1973 homosexuality was declassified as a mental illness in the United Kingdom. In 1986 all references to homosexuality as a psychiatric disorder were removed from the Diagnostic and Statistical Manual of Mental Disorders (DSM) of the American Psychiatric Association.

\section{Homosexuality in India}

Homosexuality is generally a forbidden subject in Indian common society and for the legislature. Area 377 of the Indian Penal Code makes sex with persons of the same sex deserving of law. On 2 July 2009, in Naz Foundation v. Govt. of NCT of Delhi, the Delhi High Court held that procurement to be unlawful concerning sex between consenting grown-ups, however the Supreme Court of India toppled that controlling on 11 December 2013, expressing that the Court was rather conceding to Indian administrators to give the looked for after clarity. Homophobia is predominant in India. Open dialog of homosexuality in India has been restrained by the way that sexuality in any structure is infrequently talked about candidly. As of late, however, mentality towards homosexuality has moved marginally. Specifically, there have been more portrayals and dialogs of homosexuality in the Indian news media and in Bollywood Several associations, including the Naz Foundation (India) Trust, the National AIDS Control Organization, Law Commission of India, Union Health Ministry, National Human Rights Commission of India and the Planning Commission of India, , have communicated backing for decriminalizing homosexuality in India, and pushed for tolerance and social balance for lesbian, gay, cross-sexual, and transgender individuals. India is among nations with a social component of a third sexual orientation. However mental, physical, enthusiastic and financial viciousness against LGBT group in India predominates. Needing backing from family, society or police numerous gay assault exploited people stay don't report the criminal acts.

\section{HISTORY}

- There are a numbers of ancient Indian texts which are relevant to modern LGBT causes. The Arthasastra, an ancient Indian treatise on statecraft, mentions a wide variety of nonvaginal sexual practices which, whether performed with a man or a woman, were sought to be punished with the lowest grade of fine. While homosexual intercourse was not sanctioned, it was treated as a very minor offence, and several kinds of heterosexual intercourse were punished more severely. Sex between non-virgin women incurred a very small fine, while homosexual intercourse between men was sought to be censured by a prescription of a bath with one's clothes on, and a penance of "eating the five products of the cow and keeping a one-night fast"- the penance being a replacement of the traditional concept of homosexual intercourse resulting in a loss of caste. Religion has played a role in shaping Indian customs and traditions. While homosexuality has not been explicitly mentioned in the religious texts central to Hinduism, the largest religion in India, Hinduism has taken various positions, ranging from positive to neutral or antagonistic. 


\section{Homosexuality: Road to Visibility}

Rigveda, one of the four canonical sacred texts of Hinduism says VikritiEvamPrakriti (Sanskrit: विकृतिःएवम्प्रकृतिः। meaning what seems un-natural is also natural), which some scholars believe recognizes homosexual/transsexual dimensions of human life, like all forms of universal diversities. Historical literary evidence indicates that homosexuality has been prevalent across the Indian subcontinent throughout history, and that homosexuals theyre not necessarily considered inferior in any way until about 18th century.

- The British Raj banned homosexual relations under Section 377 of the Indian Penal Code, which entered into force in 1861. It was similarly instituted throughout most of the British Empire due to the Christian religious beliefs of the British colonial governments.

\section{MODERN INDIA}

- In 1977 Shakuntala Devi published the first study of homosexuality in India. Whilst convictions under Section 377 are rare, with no convictions at all for homosexual intercourse in the twenty years, Human Rights Watch have said that the law was used to harass HIV/AIDS prevention activists, as they as sex workers, men who have sex with men, and other LGBT groups. The group documents arrests in Lucknow of four men in 2006 and another four in 2001. The People's Union for Civil Liberties has published two reports of the rights violations faced by sexual minorities and, in particular, transsexuals (hijras and kothis) in India. Homosexual intercourse was a criminal offence until 2009 under Section 377 of the Indian Penal Code, 1860. This made it an offence for a person to voluntarily have "carnal intercourse against the order of nature."

- This law was struck down by the 2009 Delhi High Court decision Naz Foundation v. Govt. of NCT of Delhi, which found Section 377 and other legal prohibitions against same-sex conduct to be in direct violation of fundamental rights provided by the Indian Constitution. Decisions of a High Court on the constitutionality of a law (i.e. judicial review)apply throughout India, and not just to the territory of the state over which the High Court in question has jurisdiction However, even after the pronouncement of verdict, there have been (rare) incidents of harassment of homosexual groups. On 16 February 2012, the Supreme Court, during a hearing of a bunch of appeals filed against decriminalisation of gay sex, observed that homosexuality should be seen in the context of changing society as many things which were earlier unacceptable have become acceptable with passage of time. The two-judge bench, composed of Justices G S Singhvi and S J Mukhopadhaya, opined that homosexuality should be seen in the light of changing times where phenomena of live-in relationship, single parents and artificial fertilisation have become normal. They had also pointed out that many things, which were considered immoral 20 years ago, have become acceptable to society now. The bench said that gay sex was not an offence prior to 1860 and referred to paintings and sculptures of Khajuraho. Senior Advocate AmrendraSharan, who opposed the Delhi High Court order of decriminalising gay sex on behalf of the Delhi Commission for Protection of Child Rights, had then submitted that social issues cannot be decided on the basis of 


\section{Homosexuality: Road to Visibility}

sculptures. The apex court bench, however, observed that it is a reflection of society of that time and homosexuality should not be seen only in terms of sexual intercourse."This is highly immoral and against the social order," the Home Ministry told the apex court. It said that India's moral and social values were different from other countries, and therefore, the nation should not be guided by them. The Central Government reversed its stand on 28 February 2012, asserting that there was no error in decriminalising gay sex. This resulted in the SC pulling up the Centre for frequently changing its stand on the issue. Don't make a mockery of the system and don't wastes the court's time, an apex court judge told the government. Also in 2012, a guide titled 'Creating Inclusive Workplaces for LGBT Employees in India' was developed by IBM, Goldman Sachs, Google together with Community Business, a non-profit organization.

\section{HOMOSEXUALITY \& MENTAL HEALTH PROBLEMS}

The American Psychiatric Association expelled homosexuality from its indicative rundown of mental issue in 1973, notwithstanding considerable challenge (see Socarides, 1995). The APA. was emphatically roused by the craving to lessen the impacts of social persecution. however, one impact of the APA's activity was to add psychiatric power to gay activists' requirement that gay people as a gathering are as sound as heterosexuals. This has debilitated production of research that proposes there may, indeed, be psychiatric issues connected with homosexuality. In 1991 without a doubt the correspondence of homosexuality and heterosexuality was unequivocally safeguarded in a paper called "The Empirical Basis for the Demise of the Mental Illness Model" (Gonsiorek, 1991). In any case not until 1992 was homosexuality dropped from the psychiatric manual utilized by different countries -the International Classification of Diseases (King and Bartlett, 1999)- -so it shows up whatever remains of the world questioned the APA 1973 choice for almost two decades.

The diathesis-stress model recommends that natural vulnerabilities incline people to diverse conditions, for example, malignancy, coronary illness, and mental wellbeing conditions like real misery, a danger component for suicide. Fluctuating measures of ecological anxiety expand the likelihood that these people will create that condition. Minority stress hypothesis proposes that minority status prompts expanded separation from the social environment which prompts more noteworthy anxiety and wellbeing issues. In the vicinity of poor feeling regulation aptitudes this can prompt poor mental wellbeing. Additionally, the differential powerlessness theory recommends that for a few people their physical and mental advancement is exceedingly subject to their surroundings in a "for-better-and-for-more regrettable" design. That is, people who are profoundly defenceless will have better than normal wellbeing in very steady situations and essentially more terrible than normal wellbeing in threatening, rough situations. The model can help clarify the special wellbeing issues influencing LGBT populaces including expanded suicide endeavours. For teenagers, the most pertinent situations are the family, neighborhood, and school. Youthful harassing - which is exceedingly common among sexual minority young 
people - is a perpetual stressor that can build hazard for suicide by means of the diathesis-anxiety model.

Homosexual depression may also be a problem because many lesbian, gay, bisexual and transgender (LGBT) people feel uncomfortable coming out to their doctor or other healthcare provider and discussing issues pertinent to homosexuality. However, the Gay and Lesbian Medical Association (GLMA) lists depression and anxiety among the top ten things that gay people need to discuss with their doctors. Other important things to discuss with your doctor that can also help with gay depression include:

-Coming out to your provider - this can put any homosexual depression you may be facing into context

-Sexually-transmitted diseases/infections and safe sex

-Substance use (including cigarettes and alcohol) - substance use is closely linked to depression

HOMOSEXUAL ANXIETY AND OCD

Having intrusive thoughts about homosexuality and doubting one's own sexuality are symptoms that characterize a subtype of Obsessive-Compulsive Disorder, sometimes called homosexual anxiety, Homosexual OCD or "H"-OCD.

This article includes a few guidelines you may want to consider to help you understand the difference between suffering from homosexual anxiety (HOCD) and actually being gay.

- Recurrent doubts about one's own sexuality

- Unwanted or intrusive thoughts about being gay

- Inability to get rid of unwanted worries or intrusive thoughts about being gay

- Seeing a member of the same sex causes anxiety and triggers unwanted thoughts about being gay

- Avoidance of members of the same sex for fear of unwanted thoughts or anxiety

- Thoughts or worries about giving off signals that one may be homosexual

- Repeating mundane actions for fear that these actions may have been performed in a "homosexual" way or a way that may signal homosexuality in the person (for example, a male may feel the need to get up from a chair and sit back down in it if he feels that the way he sat in the chair was "feminine," or a male may worry that the way he walks is too "feminine" or signals homosexuality)

- Repeating an action may relieve anxiety, but then the person feels the need to repeat the action (or ritual) again and again to relieve anxiety

- Anxiety over being gay is in opposition to one's own values and desires

- One feels that the thoughts are unacceptable and inappropriate

- Homosexual thoughts are repugnant rather than arousing

So, how can I tell the difference between being gay and having Homosexual Anxiety (HOCD)?

Gay individuals may encounter tension connected with their sexual introduction. However $\mathrm{r}$, these nerves normally stem more from the social shame appended to homosexuality and the extra 


\section{Homosexuality: Road to Visibility}

challenges that gay people may experience in discovering dating accomplices. Gay individuals may encounter enough uneasiness about making their sexual inclination realized that they may keep their sexuality a mystery or abstain from dating by and large. However, this tension is not the same as the nervousness that an individual with HOCD encounters. People experiencing HOCD have a repeating stress that they may be gay person and continually remind and promise themselves that they are hetero. HOCD sufferers may have musings that are unrelenting to the point that they evade circumstances where these contemplations are liable to happen, for example, circumstances with high contact with parts of the same sex (locker rooms, and so on.). People with HOCD regularly expect that they are gay person despite the fact that they may have dated a few individuals of the inverse sex and feel no fascination towards parts of the same sex. Albeit sexual introduction creates over an individual's lifetime, it is not inconceivable for an individual to encounter a sudden change in their introduction. However, most individuals who are gay report feeling unique in relation to their same-sex peers at an early age. Analysts have discovered youth sexual orientation resistance to be the biggest indicator of homosexuality in adulthood. Individuals who are gay are a great deal more inclined to have favoured inverse sex exercises and mates as youngsters. This is not typically the situation for individuals with HOCD.

\section{Suicide among LGBT youth}

Researchers have found that attempted suicide rates and suicidal ideation among lesbian, gay, bisexual, transgender, queer, and questioning (LGBTQQ) youth is comparatively higher than among the general population. LGBT teens and young adults have one of the highest rates of suicide attempts. According to some groups, this is linked to heterocentric cultures and institutionalised homophobia in some cases, including the use of rights and protections for LGBT people as a political they judge issue like in the contemporary efforts to halt legalising same-sex marriages. Depression and drug use among LGBT people have both been shown to increase significantly after new laws that discriminate against gay people are passed.

Bullying of LGBT youth has been shown to be a contributing factor in many suicides, even if not all of the attacks have been specifically addressing sexuality or gender. Since a series of suicides in the early 2000s, more attention has been focused on the issues and underlying causes in an effort to reduce suicides among LGBTQ youth. The Family Acceptance Project's research has demonstrated that "parental acceptance, and even neutrality, with regard to a child's sexual orientation" can bring down the attempted suicide rate. Suicidal ideation and attempts seem to be roughly the same for heterosexual youth as for youth counterparts who have same-sex attractions and behaviour but do not identify as being LGBTQ. This correlates with the findings of a large survey of US adults that found higher rates of "mood and anxiety disorders, key risk factors for suicidal behaviour," are linked to people who identify as gay, lesbian, and bisexual, rather than sexual behaviours, especially for men. The National Action Alliance for Suicide Prevention notes there are no national data (for the U.S.) regarding suicidal ideation or suicide rates among the LGBT population as a whole or in part, for LGBT youth or LGBT seniors, for example. In part because there is no agreed percentage of the national population that is LGBTQ, or even 


\section{Homosexuality: Road to Visibility}

identifies as LGBTQ, also death certificates do not include sexuality information. A 1986 study noted that previous large scale studies of completed suicides did not "consider sexual orientation in their data analyses.

\section{Current Status of Homosexuality}

Laws affecting lesbian, gay, bisexual, and transgender (LGBT) people vary greatly by country or territory - everything from legal recognition of same-sex marriage or other types of partnerships, to the death penalty as punishment for same-sex romantic/sexual activity or identity.

LGBT rights are considered human rights and civil rights. LGBT rights laws include, but are not limited to, the following:

- allowing of men who have sex with men to donate blood,

- government recognition of same-sex relationships (such as via same-sex marriage or similar unions),

- allowing of LGBT adoption,

- recognition of LGBT parenting,

- anti-bullying legislation and student non-discrimination laws to protect LGBT children and/or students,

- immigration equality laws,

- $\quad$ anti-discrimination laws for employment and housing,

- hate crime laws providing enhanced criminal penalties for prejudice-motivated violence against LGBT people,

- equal age of consent laws,

- equal access to assisted reproductive technology

- access to sex reassignment surgery and hormone replacement therapy

- legal recognition and accommodation of reassigned gender,

- and laws related to sexual orientation and military service.

Against LGBT laws incorporate, yet are not restricted to, the accompanying: homosexuality laws punishing consensual same-sex sexual movement with fines, prison terms, or capital punishment, hostile to "lesbianism" laws, and higher periods of assent for same-sex action.

In 2011, the United Nations Human Rights Council passed its first determination perceiving LGBT rights, which were caught up with a report from the UN Human Rights Commission recording infringement of the privileges of LGBT individuals, including disdain wrongdoing, criminalization of homosexuality, and separation. Catching up on the report, the UN Human Rights Commission urged all nations which had not yet done so to order laws securing fundamental LGBT rights. 
Table No 1: showing status of LGBT in different countries

\begin{tabular}{|c|c|c|c|c|}
\hline $\begin{array}{l}\text { LGBT Rights } \\
\text { In : }\end{array}$ & Recognition & $\begin{array}{ll}\text { Same } & \text { Sex } \\
\text { Marriage } & \end{array}$ & Adoption & $\begin{array}{l}\text { Laws } \\
\text { Concerning } \\
\text { Gender Identity }\end{array}$ \\
\hline Egypt & No & No & No & No \\
\hline Morroco & No & No & No & No \\
\hline $\begin{array}{l}\text { Central } \\
\text { African } \\
\text { Republic }\end{array}$ & Yes & No & No & No \\
\hline $\begin{array}{l}\text { Republic of } \\
\text { congo }\end{array}$ & Yes & No & No & No \\
\hline Ethopia & $\begin{array}{l}\text { No : 10years of } \\
\text { imprisonment }\end{array}$ & No & No & No \\
\hline South Africa & 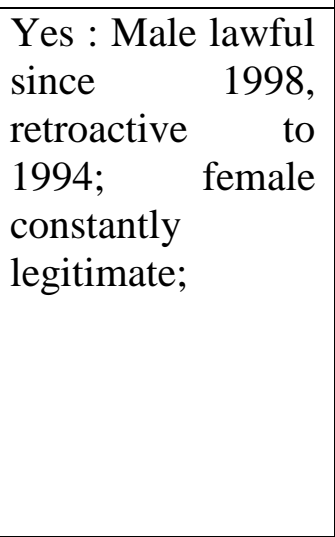 & $\begin{array}{l}\text { Restricted } \\
\text { distinguish of } \\
\text { unregistered } \\
\text { organizations } \\
\text { since 1998; } \\
\text { Same-sex } \\
\text { marriage since } \\
\text { 2006. }\end{array}$ & $\begin{array}{ll}\text { Legal since } \\
2006\end{array}$ & $\begin{array}{l}\text { Against } \\
\text { segregation laws } \\
\text { are deciphered to } \\
\text { incorporate sex } \\
\text { personality; } \\
\text { lawful sexual } \\
\text { orientation may } \\
\text { be changed after } \\
\text { surgical or } \\
\text { medicinal } \\
\text { treatment. }\end{array}$ \\
\hline Canada & Yes & $\begin{array}{l}\text { Yes : Legal } \\
\text { since } 2005\end{array}$ & $\begin{array}{l}\text { Yes : legal } \\
\text { nationwide but } \\
\text { varies }\end{array}$ & $\begin{array}{l}\text { Legitimate } \\
\text { distinguish } \\
\text { however just } \\
\text { allowed after } \\
\text { consummation } \\
\text { of restorative } \\
\text { mediation in } \\
\text { many regions } \\
\text { and domains (not } \\
\text { needed in } \\
\text { Ontario); }\end{array}$ \\
\hline Mexico & Yes & $\begin{array}{l}\text { Legal since } \\
2013\end{array}$ & $\begin{array}{l}\text { Legal since } \\
2013\end{array}$ & $\begin{array}{l}\text { Yes : requires } \\
\text { sterlization }\end{array}$ \\
\hline United states & $\begin{array}{l}\text { Varies according } \\
\text { to state }\end{array}$ & $\begin{array}{l}\text { Varies } \\
\text { according to } \\
\text { state }\end{array}$ & $\begin{array}{lr}\text { Laws } & \text { varies } \\
\text { according } & \text { to } \\
\text { state } & \end{array}$ & $\begin{array}{l}\text { Sex personality } \\
\text { separation in } \\
\text { occupation and } \\
\text { human services } \\
\text { protection } \\
\text { banned since } \\
2012 \text {. }\end{array}$ \\
\hline
\end{tabular}


Homosexuality: Road to Visibility

\begin{tabular}{|c|c|c|c|c|}
\hline Argentina & $\begin{array}{l}\text { Yes } \\
: \quad \text { Unregistered } \\
\text { cohabitation } \\
\text { throughout the } \\
\text { country }\end{array}$ & $\begin{array}{l}\text { Yes : Legal } \\
\text { since } 2010\end{array}$ & $\begin{array}{l}\text { Yes : Legal } \\
\text { since } 2010 .\end{array}$ & $\begin{array}{l}\text { Yes : } \\
\text { transgender } \\
\text { persons can } \\
\text { change their } \\
\text { legal gender and } \\
\text { name without } \\
\text { surgeries or } \\
\text { judicial } \\
\text { permission } \\
\end{array}$ \\
\hline Brazil & $\begin{array}{l}\text { Yes : } \\
\text { unions" } \\
\text { since 2004, lawfule } \\
\text { All rights as } \\
\text { perceived family } \\
\text { elements } \\
\text { accessible across } \\
\text { the nation since } \\
2011\end{array}$ & $\begin{array}{l}\text { Yes : Legal } \\
\text { since } 2011 \\
\text { (given } \\
\text { translation of } \\
\text { "stable union" } \\
\text { enactment), } \\
\text { Across the } \\
\text { nation since } \\
2013\end{array}$ & $\begin{array}{l}\text { Yes : Single } \\
\text { gay persons } \\
\text { explicitly } \\
\text { accepted } \\
\text { 1996, } \\
\text { Legal } \\
\text { 2010 since } \\
\end{array}$ & $\begin{array}{l}\text { Yes : Legal } \\
\text { gender and name } \\
\text { changes since } \\
2009 \text {, though } \\
\text { SRS - legal }\end{array}$ \\
\hline Iraq & $\begin{array}{l}\text { Yes : legal since } \\
2003\end{array}$ & No & No & No \\
\hline India & $\begin{array}{l}\text { No : illegal since } \\
\text { 1860,10years } \\
\text { imprisonment }\end{array}$ & No & No & $\begin{array}{l}3^{\text {rd }} \text { gender } \\
\text { recognized }\end{array}$ \\
\hline
\end{tabular}

\section{REVIEW OF LITERATURE}

1. Being gay is as being straight by Dr. Evelyn Hooker (1950)

In the 1950's, Dr. Evelyn Hooker considered 30 gay person males and 30 heterosexuals males were enrolled through group associations. The two gatherings were matched for age, IQ, and instruction. Dr. Hooker regulated three projective tests, which measure individuals' examples of contemplations, demeanour, and feelings -the Rorschach, in which individuals portray what they see in conceptual ink smears, the Thematic Apperception Test and the Make-A-Picture-Story [maps] Test), in which individuals inform stories regarding diverse pictures. They grouped twothirds of the heterosexuals and two-thirds of the gay people in the three most elevated classes of change. Dr. Hooker likely recommended that gay people are as mentally typical as heterosexuals.

\section{Impact of the Decriminalization of Homosexuality in Delhi: An Empirical Study, JANUARY 13, 2013}

On July 2, 2009, the Delhi High Court read down Chapter XVI, Section 377 of the Indian Penal Code. Preceding the Court's decision, Section 377 criminalized sexual movement "against the request of nature, and served basically as a vehicle for criminal approval of male gay person action. In its memorable judgment, the Delhi High Court found that the procurement disregarded Article 14 and 21 of the Indian Constitution, which accommodates the correspondence of all Indian residents and the right to live with nobility. The exploration led for this study comprises for the most part of individual meetings with parts of the LGBT group. Specialists associated 


\section{Homosexuality: Road to Visibility}

with people having a place with diverse sexual minorities who depicted their lives prior and then afterward July 2, 2009. The discoveries of the meetings are predictable with comparative studies in different nations, for example, South Africa, the United States, Canada, and Australia. The discoveries of this report plainly demonstrate that the Delhi High Court judgment has absolutely affected the LGBT group and has enhanced the personal satisfaction of sexual minorities.

\section{A genetic study of male sexual orientation by Bailey JM, Pillard RC(1993)}

Gay person male probands with monozygotic cotwins, dizygotic cotwins, or adoptive siblings were enlisted utilizing homophile distributions. Sexual introduction of relatives was surveyed either by asking relatives specifically, or when this was unimaginable, asking the probands. Of the relatives whose sexual introduction could be appraised, 52\% (29/56) of monozygotic cotwins, 22\% (12/54) of dizygotic cotwins, and 11\% (6/57) of assenting siblings are gay person. Heritabilityis significant under an extensive variety of suppositions about the populace base rate of homosexuality and ascertainment inclination. However, the rate of homosexuality among nontwin natural kin, as reported by probands, 9.2\% (13/142), was essentially lower than would be anticipated by a straightforward hereditary speculation and other distributed reports. A probands self-reported history of youth sexual orientation non-congruity did not foresee homosexuality in relatives in any of the three subsamples. Accordingly, adolescence sexual orientation resistance does not have all the earmarks of being a marker of hereditary stacking for homosexuality. Cotwins from concordant monozygotic sets are fundamentally the same for adolescence sexual orientation individuality.

\section{New data on lesbian, gay and bisexual mental health by TORI DeANGELIS, February 2002}

A few substantial populations based open wellbeing studies are talked about in the November American Psychologist (Vol. 56, No. 11) by Susan Cochran, Phd, a disease transmission specialist in the University of California, Los Angeles School of Public Health, who composed or co-wrote a significant number of the studies. Particularly, the studies find:

-higher rates of significant sorrow, summed up nervousness issue and substance utilize or reliance as a part of lesbian and gay youth.

-higher rates of repetitive real gloom are among gay men.

-higher rates of uneasiness, disposition and substance utilization issue, and selfdestructive contemplations among individuals ages 15 to 54 with same-sex accomplices. -higher utilization of mental wellbeing administrations are in men and women reporting same-sex.

\section{Are homosexuals mentally ill? By N.E.Whitehead ( 2002)}

Most gay people are not rationally sick. However, late studies show gay people are at much more serious danger than heterosexuals, especially for substance ill-use, suicide, sadness, bulimia and introverted identity issue. This paper highlights some new and noteworthy focuses in those papers, furthermore contends that some more amazing manifestations of gay person conduct are in themselves an emotional sickness, however not by present DSM criteria. Those demonstrating such practices are the individuals to the least extent liable to present themselves as customers for therapy. Secondly, it was long ago noted (Carlat et al. 1997) that $43 \%$ of a bulimic specimen of 


\section{Homosexuality: Road to Visibility}

men isgay person or promiscuous, a rate around 15 times higher than anticipated, and significance gay person men are lopsidedly subject to this mental condition. This presumably emerges from the exceptionally solid distraction with appearance and figure habitually found among male gay people.

\section{What Causes Homosexual Desire and Can It Be Changed? By Paul Cameron, Ph. D. (2000)}

To the normal individual, the general concept is either bewildering or repulsive. Undoubtedly, a late overview (1) showed that just $14 \%$ of men and $10 \%$ of ladies envisioned that such conduct could old any "plausibility of enjoyment. Homosexual conduct is an unfortunate propensity that individuals fall into on the grounds that they are sexually tolerant and trial. This perspective holds rodent gay people pick their way of life as the consequence of liberality and unwillingness to play by society guidelines. The second position is held by various psychoanalysts (e.g., Bieber, Socarides). As indicated by them, gay person conduct is an emotional instability, symptomatic of captured advancement. They accept that gay people have unnatural or unreasonable longings as an outcome of poor familial relations in adolescence or some other trauma. The third view is "organic" and holds that such wishes are hereditary or hormonal in cause, and that there is no decision included and no "youth trauma" vital.

7. Homosexuality: Nature or nurture by Ryan D. Johnson et al. (2003)

Organic scholars have discovered significant examples of anatomical, hereditary, and endocrine confirmation to backing their contention. The spearheading examination of Alfred Kinsley turned into the generally promoted Kinsley Scale of Sexuality. In 1957, Karen Hooker executed the first mental test for natural determinism on both gay people and heterosexuals and finished up a zero association between social determinism of sexuality. As an aftereffect of Hooker's discovering, the American Psychological Association (APA) expelled homosexuality from its Diagnostic and Statistical Manual of Psychological Disorders in 1973. In 1990, Swaab found in his after death examination of gay person guys' brains that an allotment of the hypothalamus (suprachiasmatic core) was double the extent of its hetero partners. In 1991, Simon Levay directed an alternate probe hypothalamus of the human mind and inferred that gay person and hetero men contrast in the focal neuronal systems that control sexual conduct. This distinction in life structures was no result of childhood nature, yet rather pre-birth cerebral improvement and structural separation. In two different studies, Ernest Kallman and Micheal Bailey and Richard Pillard discovered a higher concordance rate among monozygotic twins proposing a hereditary connection. Later on, Hamer analysed the likelihood of homosexuality being a X-connected characteristic. Most social scholars see adolescence components as the biggest helping variables to homosexuality. Frequently they inspect youth play designs, early companion associations and relations, contrasts in parental conduct to male and female kids, and the part of sexual orientation steadiness in the family unit.

Maybe there is no answer that sexual orientation, whether gay person or hetero, gay, straight, lesbian, or androgynous, all are a reason for a complex association between ecological, cognitive, and anatomical components, forming the single person at an early age. 


\section{Homosexuality: Road to Visibility}

\section{The health risks of gay sex by DIGGS JR. (2008)}

Sexual connections between parts of the same sex uncover gays, lesbians, and bisexuals (GLB) to amazing dangers of sexually transmitted illnesses .There are five significant qualifications between gay and hetero connections regarding, levels of wantonness, physical wellbeing, mental wellbeing, life compass, and monogamy. Before the AIDS pestilence, a 1978 study found that 75 percent of white, gay guys asserted to have had more than 100 lifetime male sex accomplices. From 1994-1997, the rate of gay person men reporting different accomplices and unprotected butt-centric sex rose from $23.6 \%$ to $33.3 \%$, which is biggest among men under 25 years old. The therapeutic outcome of this indiscrimination is that gays have a significantly improved probability of contracting HIV/AIDS, syphilis, and different Standards. Infections like buttcentric growth, giardiasis, amoebiasis, hepatitis B and C, kaposi's sarcoma, HIV, and so on are found in uncommon recurrence among male gay person specialists. One study reported that $66 \%$ of gay couples reported sex outside the relationship inside the first year, and about $90 \%$ if the relationship kept going five years. Swaying individuals to take part in hazardous sexual conduct undermines great wellbeing and can bring about an abbreviated life compass. Yet that is precisely what businesses and administrative substances are doing when they allow GLB couples profits or status that make GLB connections seem all the more socially worthy.

\section{Criminalising high-risk groups such as MSM by Kavi AR. (2008)}

Each of the three centre gatherings influenced and tainted in the HIV pestilence - men having intercourse with men (MSM), sex specialists, and infusing medication clients - are criminalized in India. These centre gatherings are undetectable to wellbeing structure as well as disparaged and criminalized under Indian law, so the legislature needed to inquiry and chase these populaces. MSM in India are at critical danger of HIV contamination in light of continuous buttcentric sex (45-55\% of MSM in India rehearse butt-centric sex), rare utilization of condom for butt-centric sex (5-20\%), extensive number of accomplices (between 11-28 cool accomplices for every month), and weakness looking for conduct, with just 20-30\% of MSM striving for STI check-up. In India, just in the third phase of the National AIDS Control Program (NACP- III) did the NACO recognize that MSM obliged pressing consideration? Behaviourally gay person populace has at long last been recognized as a centre fragment with which national wellbeing projects need to captivate genuinely if NACP III is to have a pinch of achievement. The system is yet to address some significant challenges in giving help administrations to MSM. There is no affectability to MSM issues. STI centres regulated at oral or butt-centric sex administrations don't exist, and STI specialists are not socially sharpened to MSM issues. Further, MSM group based associations are not urged to take up wellbeing issues which specifically influence their groups. Essential structural progressions are vital for wellbeing projects to be powerful. These incorporate cancellation or perusing down of Section 377 of the Indian Penal Code on homosexuality, decriminalizing sex work, and changing the methodology to opiates control by tightening up on trafficking and not rebuffing end-clients. At exactly that point would they be able to unabashedly discuss defamed practices like butt-centric sex, intravenous medication utilize, and sex work, and captivate these gatherings. 


\section{Homosexuality: Road to Visibility}

\section{Medical consequences of what homosexuals do by Paul Cameron (2008)}

Gay people carry on comparatively world over and the progressions in sexual conduct that have been accounted for to have happened in a few gatherings have ended up being, transient. Gay people fellate practically the greater part of their sexual contacts amid oral sex, ingesting semen, and in this manner expanding danger of contracting diseases like hepatitis A, B, and gonorrhoea. Very nearly $90 \%$ of gays participate in rectal intercourse. It is presumably the most sexually proficient approach to spread hepatitis B, HIV, and so forth as sperms promptly enter the rectal divider (one cell layer thick) bringing about immunological harm. Tearing and wounding of buttcentric divider happens amid butt-centric sex or fisting, which further upgrades the powerlessness to contamination. Around $80 \%$ of gays confess to faecal sex. It is the real course of contracting hepatitis A, typhoid fever, and other enteric parasites. Around $29 \%$ showed up for take part in pee sex. A hefty portion of them take part in sadomasochism, that is, they participate in torment for sexual fun. The average period of death for gay people was 39 years if AIDS was the reason for death and 42 years in the event that they passed on of an option that is other than AIDS. Short of what $2 \%$ made due to maturity. Two point eight percent of gays kicked the bucket fiercely. They are 116 times more adept to be killed; 24 times more able to confer suicide; and had a car crash passing - rate 18 times the rate - contrasted with matured white guys. Heart assaults, disease, and liver failure are especially normal. Twenty percent of lesbians passed on of homicide, suicide, or mischance - a rate 487 times higher than that of white females matured 2544 years. Gay people are sexually vexed individuals participating in risky exercises. Since they think about them and those enticed to go along with them, it is essential they not empower or legitimize such a damaging way of life.

11. Homosexual Persons, Behaviours, and Civil Rights A Meta-Analysis by Mary E. Kite , Bernard E. Whitley Jr.(1996)

Meta-scientific strategies they are utilized to analyse men's and ladies' demeanour to gay person persons, gay person practices, and gay individuals' social equality. Not surprisingly, size of sex contrasts differed over these classes. Men they are more contrary than ladies to gay person persons and gay person conduct, however the genders viewed gay social equality likewise. Men's mentality to gay person persons are especially contrary when the individual being appraised was a gay man or of unspecified sex. Ladies and men assessed lesbians correspondingly. Appraisals of gay person persons and gay person conduct to the least extent liable to contrast by subject sex for examples of nonprofessional grown-ups. Likewise, sex part demeanour intervened sex contrasts in mentality to homosexuality. Predispositions in the exploration writing and ranges that merit further consideration, for example, the perplexing of specimen with estimation technique and the propensity to study gay men or focuses of unspecified sex, are talked about.

12. Predictors of Identity Management: An Exploratory Experience-Sampling Study of Lesbian, Gay, and Bisexual Workers by Eden B. King , Jonathan J. Mohr , Chad I. Peddie , Kristen P. Jones ,Matt Kendra( published 2014)

This study analysed work environment connections in which lesbian, gay, and swinger (LGB) specialists confronted choices identified with uncovering or covering their LGB characters at work (i.e., character administration circumstances). Members' are 61 LGB grown-ups who 


\section{Homosexuality: Road to Visibility}

finished a benchmark review about their association and, in excess of 3 weeks, reacted to occasion based studies quickly after character administration circumstances. Results proposed that LGB labourers deal with their criticized personality deliberately as indicated by situational attributes. Undoubtedly, a significant part of the fluctuation being used of uncovering and hiding methods was because of contrasts inside individuals from circumstance to circumstance. Utilization of character administration systems was anticipated by cooperation accomplice prompts of acknowledgement or dismissal as they'll as impression of LGB-related hierarchical atmosphere and arrangements. Results at the inside individual and between-individual levels veered in critical ways.

13. Religion and Support for Adoption by Same-Sex Couples : The Relative Effects of Religious Tradition, Practices, and Beliefs : Andrew L. Whitehead, Samuel L. Perry( published 2014)

This article looks at the relative effect of religious variables on Americans' mentality to reception by same-sex couples. Drawing upon national overview information, they fit logistic relapse models and register institutionalized logistic relapse coefficients to gauge the relative net impacts of religious custom, practices, and convictions about the Bible on backing for same-sex selection. Discoveries uncover that religious components are among the strongest indicators of restriction to same-sex reception, however that religious custom has no critical impact on backing for same-sex appropriation once recurrence of religious practice and convictions about the Bible are held consistent. Americans who all the more habitually take part in practices, for example, religious administration participation and hallowed content perusing are less steady of same-sex selection, and contrasted with bible founded literalists, the individuals who accept the Bible obliges understanding, contains human mistake, or is a book of history/legends are all more prone to help same-sex reception. Discoveries recommend that religious affiliations matter less for anticipating same-sex reception demeanour than how Americans practice and hold their confidence.

14. A regulatory fit perspective in majority versus minority support to attitudes toward homosexuals : Juan M. Falomir-Pichastor , Gabriel Mugny , FabriceGabarrot

Three studies analysed the mentality to gay people as a capacity of administrative centre and social backing for non-separation. Administrative introduction to non-segregation was measured by separating advancement and counteractive action feelings when envisioning a non-unfair (studies 1 and 2) and a biased connection with gay people (examine 2). Study 3 evaluated mentality to non-separation through a social predominance introduction (SDO) scale and controlled tentatively administrative centring. Over the three studies, social backing was controlled by advising members that either a lion's share or a minority of the Swiss populace backed non-segregation when all is said in done (study 1), or particularly to gay people (contemplates 2 and 3). Results showed more uplifting disposition to gay people when nonbiased members are directed regarding counteractive action centre and non-separation was upheld by a greater part, and when non-unfair members are controlled as far as advancement centre and non-segregation was underpinned by a minority. These discoveries are reliable with 


\section{Homosexuality: Road to Visibility}

an administrative fit viewpoint on the transaction between administrative centre and social backing.

\section{Sexual Orientation Identity and Romantic Relationship Quality in Same-Sex Couples} :Jonathan J. Mohr, Ruth E. Fassinger

Investigation proposes that the well-being of parts of demonized gatherings is identified with the ways that people comprehend, assess, and react to their degraded aggregate character. The present study amplifies this line of request by examining aggregate personality in the setting of sentimental relationship working, concentrating on same-sex couples as a sort of defamed relationship. In this cross-sectional study, the creators analysed four character related variables (disguised homonegativity, disgrace affectability, personality perplexity, and character prevalence) in a specimen of 274 female and 187 male same-sex couples. Results gave proof of personality similitude between accomplices, especially for disguised homonegativity and character predominance. Each of the character variables was connected with relationship quality, and performing artist impacts of personality on quality are more regular than accomplice impacts. Saw character likeness interceded a portion of the connections discovered between personality and quality and was emphatically connected with relationship quality paying little respect to performing artist personality.

16. Formal and Interpersonal Discrimination: A Field Study of Bias Toward Homosexual Applicants : Michelle R. Hebl , Laura M. Manni : John F. Dovidio

The current research studies segregation from the point of view of individuals in slandered parts in real livelihood settings. Confederates, who are depicted as being gay person or not, requested occupations at nearby stores. Measures of formal inclination (e.g., employment offers), interpersonal conduct (e.g., length of collaborations), and view of predisposition (e.g., foreseen occupation offers by candidates) are evaluated. Despite the fact that confederates depicted as gay person are not victimized in formal routes in respect to confederate candidates not introduced as gay, they are reacted to essentially all the more adversely in interpersonal ways. Besides, there was a stronger relationship between interpersonal treatment and expected work activities for confederates than there was between interpersonal reactions and real employment offers by bosses. These discoveries uncover the elements of the advancement of distinctive impressions and desire by stigmatises and targets. Hypothetical and handy ramifications are considered.

17. Beyond "homophobia": A social psychological perspective on attitudes toward lesbians and gay men by Herek, G.M. (1984).

Homophobia, a term regularly used to depict antagonistic responses to lesbians and gay men, infers an one-dimensional build of demeanour as outflows of nonsensical apprehensions. This paper contends that a more perplexing perspective is required of the brain research of constructive and adverse mentality to gay person persons. Based upon a survey of past observational examination, a model is recommended that recognizes three sorts of mentality as per the social mental capacity they serve: (1) experiential, ordering social reality by one's past associations with gay person persons; (2) opposing, adapting to one's internal clashes or nerves by anticipating them onto gay person persons; and (3) typical, communicating dynamic ideological ideas that are nearly joined to one's thought of self and to one's informal organization 


\section{Homosexuality: Road to Visibility}

and reference bunches. Methodologies are proposed for changing state of mind serving each of the capacities. The imperativeness of recognizing mentality to lesbians from those concentrated on gay men is likewise tended to.

18. Attitudes toward lesbians and gay men: A factor-analytic study by Herek, G.M. (1984). This paper reports an arrangement of element breaks down of reactions to mentality articulations about lesbians and gay men. Utilizing a typical element model with slanted pivot, a bipolarcondemnation-Tolerance variable was watched more than once in four different examples of students. The variable records for $35-45 \%$ of the aggregate regular fluctuation in reactions, and is comparative for guys and female respondents and for polls concerning both lesbians and gay men. A Beliefs element represents an alternate $5 \%$ of the aggregate fluctuation. It is contended that scales surveying state of mind to lesbians and gay men ought to confine their substance to things stacking profoundly on the Condemnation-Tolerance variable. An informative supplement records things stacking on the Condemnation-Tolerance variable.

19. Heterosexuals' attitudes toward lesbians and gay men: Correlates and gender differences by Herek, G.M. (1988).

This paper examines the premise for contrasts among heterosexuals in their responses to gay individuals, with extraordinary accentuation on the issue of sexual orientation contrasts. Three studies led with understudies at 6 separate colleges uncovered a reliable inclination for hetero guys to express more unfriendly state of mind than hetero females, particularly to gay men. The same social mental variables seem to underlie both guys' and females' mentality to both gay men and lesbians: religiosity, adherence to customary philosophies of family and sexual orientation, view of companions' concurrence with one demeanour, and past cooperation with lesbians and gay men. The part of these variables in forming mentality is examined and regions for future exploration are proposed. Development and acceptance of the Attitudes toward Lesbians and Gay Men (ATLG) scale are additionally depicted.

20. Hate crimes against lesbians and gay men: Issues for research and policy by Herek, G.M. (1989).

Antigay hate crimes (words or activities that are expected to damage or threaten people in light of the fact that they are lesbian or gay) constitute a genuine national issue. In late studies, upwards of $92 \%$ of lesbians and gay men report that they have been the focuses of antigay verbal ill-use or dangers, and upwards of $24 \%$ report physical assaults in view of their sexual introduction. Strikes may have expanded in recurrence amid the last few years, with numerous episodes now including talked references to the (AIDS) by the attackers. Patterns can't be evaluated, however, on the grounds that most antigay contempt unlawful acts are never reported and no extensive national reviews of antigay exploitation have been directed. Proposals are offered for exploration and approach.

21. Modelling the impact of HIV disease on mortality in gay and bisexual men. : R S Hogg, S A Strathdee, K J Craib, M V O'Shaughnessy, J S Montaner, M T Schechter

To do survey how HIV disease and AIDS (HIV/AIDS) effects on death rates for gay and promiscuous men. Systems: Vital detail information they got for a substantial Canadian urban focus from 1987 to 1992. Three situations used with expected extents of gay and promiscuous 


\section{Homosexuality: Road to Visibility}

men of 3\%, 6\% and 9\% among the male populace age 20 years. For every situation, non-HIV passingare dispersed as per the expected extent of the aggregate populace (3\%, 6\% or 9\%) yet 95\% of HIV passingare appropriated to gay and cross-sexual men as this is the extent of AIDS cases in gay and swinger men in this middle. The principle conclusion measures of investment age-particular examples of death, future and future lost because of HIV/AIDS at definite age 20 years, and the likelihood of living from age 20 to 65 years. Evaluations of the mid-period gay and androgynous populace ran from 5406 to 16,219 for the three situations, and aggregate passing in these men from 953 to 1703. Age-particular mortality was essentially higher for gay and swinger men than all men matured 30-44. Future at age 20 for gay and swinger men ran from 34.0 years to 46.3 years for the $3 \%$ and $9 \%$ situations individually. These are all lower than the 54.3 year future at age 20 for all men. The likelihood of living from age 20 to 65 years for gay and cross-sexual men went from $32 \%$ for the $3 \%$ situation, to $59 \%$ for the $9 \%$ situation. These figures are respectably lower than for all men where the likelihood of living from 20 to 65 was $78 \%$.

\section{Genetic models of homosexuality: generating testable predictions by Sergey Gavrilets and William R Rice}

Homosexuality is a typical event in people and different species, yet its hereditary and evolutionary premise is defectively caught on. Here, the paper figure and study an arrangement of basic numerical models with the end goal of foreseeing experimental examples that can be utilized to focus the type of determination that prompts polymorphism of qualities impacting homosexuality. Particularly, they create hypothesis to make differentiating expectations about the hereditary attributes of qualities impacting homosexuality including: (i) chromosomal area, (ii) predominance among isolating alleles and (iii) impact sizes that recognize between the two significant models for their polymorphism: the overdominance and sexual enmity models. They infer that the estimation of the hereditary attributes of quantitative attribute loci found in genomic screens for qualities affecting homosexuality can be exceedingly educational in determining the type of regular choice keeping up their polymorphism.

\section{Baile and Pillard-The Famous “Twins" Study (1991)}

Michael Bailey and Richard Pillard, analysts at North eastern University and the Boston University School of Medicine, completed a comparable investigation, analysing 56 sets of indistinguishable twins, 54 sets of brotherly twins, 142 non-twin siblings of twins, and 57 sets of assenting siblings (1991). Bailey and Pillard were looking to check whether homosexuality was passed on through familial lines, or if one could indicate natural variables as the reason. Their speculation: if homosexuality is an inherited characteristic, then more twin siblings would be required to have the same introduction than non-twin or non-natural siblings.

- $52 \%$ of indistinguishable (monozygotic) twins of gay person men

- $22 \%$ of congenial (dizygotic) twins are in like manner gay person

- $11 \%$ of assenting siblings of gay person men

- 9.2\% of non-twin organic kin reported gay person introductions (Bailey and Pillard, 1991, "A Genetic Study of Male Sexual Orientation")

- $48 \%$ of indistinguishable twins of gay person are similarly gay person 


\section{Homosexuality: Road to Visibility}

- $16 \%$ of congenial (dizygotic) twins are like homosexuals

24. Sex Hormone Studies In Male Homosexuality by S.J Glass, H.J Deuel, And C.A. Wright ( 2013)

UNTIL RECENT YEARS homosexuality has been by and large thought to be of psychogenic starting point. In any case a lot of people new examinations give occasion to feel qualms about this concept. A finer knowledge into the instrument of sexual improvement and sex separation focuses to the fundamental androgyny of man. That sex inconsistencies may emerge from strange hereditary methods is substantiated by numerous perceptions on lab creatures. Rosanoff (1) has accentuated the genetic inception of homosexuality and other sexual irregularities in his hypothesis of disorganized sexuality. Wright (2) proposed a hypothesis of homosexuality focused around a sex hormone irregularity. He showed different degrees of inversion of the typical androgen-oestrogen proportion in 49 gay people. Glass and Mckennon (3) in like manner exhibited these distinctions however their information are excessively pitiful for statistical examination.

\section{Gay Brain Science: Homosexuality a Birth Defect? By James Joyner (2008)}

Researchers at the Karolinska Institute considered mind sweeps of 90 gay and straight men and ladies, and found that the extent of the two symmetrical parts of the brains of gay men more nearly looked like those of straight ladies than they did straight men. In hetero ladies, the two parts of the mind are pretty much the same size. In hetero men, the right side of the equator is marginally bigger. Outputs of the brains of gay men in the study, however, showed that their halves of the lobe were moderately symmetrical, in the same way as those of straight ladies, while the brains of lesbians were unbalanced like those of straight men.

Going deeper into the study, they see that the distinction in mind symmetry is an impact, not a reason. The in all probability reason is "hormonal impacts." It turns out, "homosexuality may be brought about by 'underexposure to pre-birth androgens' in guys and 'over-presentation' in females." This strikes me as very conceivable. Review that there was a study a few years back demonstrating that ladies who took diet pills amid pregnancy was significantly more prone to have gay youngsters.

\section{Relationship Breakups Motivate Most: Suicide Attempts by Saghir and Robins et al (1978)}

The papers demonstrate that it is gay way of life components, or society's trashing, that are the sparks that lead an individual to endeavour suicide? Not one or the other conclusion is inescapable. Still, Saghir and Robins (1978) inspected purposes behind suicide endeavours among gay people and found that if the explanations behind the endeavour are associated with homosexuality, around 2/3 are because of breakups of connections -not outside weights from society.

Likewise, Bell and Theyinberg (1981) additionally discovered the real explanation behind suicide endeavours was the separation of connections. In second place, they said, was the powerlessness to acknowledge oneself. Since gay people have more noteworthy quantities of accomplices and breakups, contrasted and heterosexuals, and since long-term gay male connections are seldom monogamous, it is barely astonishing if suicide endeavour are relatively 


\section{Homosexuality: Road to Visibility}

more prominent. The average number of accomplices for gay people is four times higher than for heterosexuals (Whitehead and Whitehead 1999, ascertained from Laumann et al 1994).a great general dependable guideline is that suicide endeavours are around three times higher for gay people. Could there be an association between those two percentages? Another figure in suicide endeavours would be the enthusiastic or addictive components in homosexuality (Pincu, 1989) which could prompt emotions of despondency when the way of life is wild (Seligman 1975). There are a few, (assessments shift, however maybe upwards of half of youngsters today), who don't take predictable safety measures against HIV (Valleroy et al., 2001) and who have extensive issues with sexual fixation and substance ill-use dependence, and this obviously would sustain into suicide endeavours.

\section{Strongly Linked to Depression and Suicide:Micheal King}

As indicated by another study, which broke down 25 prior studies in regards to sexual introduction and mental wellbeing, gay people and bisexuals are around half more probable than their hetero partners to experience the ill effects of misery and ill-use drugs. The scientists additionally found that the danger of suicide bounced in excess of $200 \%$ for the individuals who had occupied with a gay person lifestyle. While the study couldn't answer why homosexuality is joined to sadness, lead analyst Michael King estimated that is probably because of the deep rooted anxieties brought about by the segregation and dismissal that gay people and bisexuals endure from. King did note that advisors ought to be mindful about consequently expecting that a persistent wretchedness was specifically identified with their sexual introduction. "This happens often," King said, "much to the aggravation of numerous (lesbian, gay and swinger) individuals who look for treatment." Instead, King notes, advisors ought to concentrate on the wretchedness itself and just be mindful that gay person and androgynous patients are at more serious danger for mental wellbeing issue.

\section{Higher risk of mental health problems for homosexuals by Dr.Apu Chakraborty (2007)} Separation may help the higher danger, accepts lead scientist Dr.Apu Chakraborty of University College London, UK.

His group took a gander at rates of mental issue among 7,403 grown-ups living in the UK, whose points of interest got from the Adult Psychiatric Morbidity Survey 2007. Rates of misery, tension, fanatical urgent issue, fear, devilishness toward oneself, self-destructive considerations, and liquor and medication reliance are altogether higher in gay person respondents. Four percent had a depressive scene in the last week, contrasted with two percent of hetero individuals. The rate of liquor reliance was ten percent versus five percent, and for harming toward oneself it was nine percent versus five percent. "Our study affirms prior work did in the UK, USA and Holland which recommends that non-hetero individuals are at higher danger of mental issue, selfdestructive ideation, substance abuse and underhandedness toward oneself than hetero individuals." He expressed that, in spite of the fact that the level of segregation was low, it was still essentially higher than against hetero individuals. This "loans backing to the thought that individuals who feel oppressed experience social stressors, which thus builds their danger of encountering mental wellbeing issues," he says. These larger amounts of psychiatric issues in 


\section{Homosexuality: Road to Visibility}

gay person individuals call for more prominent endeavours at keeping the issues emerging, Dr. Chakraborty concludes.

\section{Homosexuality And Paranoid Schizophrenia: A Survey Of 150 Cases And Controls by Franklin S. Klaf; Charles A. Davis ( 1960)}

In this paper, the information acquired from an investigation of the records of 150 distrustful schizophrenic patients and a control gathering of 150 non-maniacal patients were introduced and talked about in connection to Freud's speculation concerning the improvement of neurotic side effects. Four outcomes of Freud's theory derived. Three of the reasoned outcomes got solid check from the study, the distinctions between the suspicious insane and control gatherings being discovered extremely critical. The fourth result, which they ought to expect the last daydreams and fantasies of the neurotic gathering to have conspicuous sexual substance, did not get check from the study. Correlation with the control bunch here was outlandish because of the unlucky deficiency of daydreams in the control group. Another indicates needs be specified concerning the present study. This is the way that two patterns may exist together in an identity but not so much be related. Few therapists debate that Freud's fruitful knowledge was gainful of numerous speculations that have extended our insight into mental working. Be that as it may, it is likewise a coherent error to contend that a hypothesis is checked in light of the fact that it clarifies certain facts. The procedure of confirmation, as used in this paper, is the same technique utilized by the dominant part of investigative examiners. They feel that the accompanying investigations of this paramount subject are needed: 1. An investigation of the relationship of homosexuality to suspicious schizophrenia in female gatherings, as contrasted and control bunches. As noted in the writing audit, there are just two non-psychoanalytic case reports managing homosexuality and jumpy schizophrenia in females.2. To think about this subject using essential source material. A convention ought to be attracted up development, including meaning of terms and classifications to be recorded. This convention ought to be utilized within questioning an arbitrary inspecting of neurotic schizophrenic patients, and a comparable gathering of non-insane patients of differing judgments. Other control gatherings might likewise be utilized. The analysts ought to be free of preconceived conclusions in regards to the relationship of homosexuality to the distrustful schizophrenic process. Until more investigative studies are made and broke down, the theory that jumpy crazy side effects create as a resistance against developing oblivious gay person wishes can't be viewed as checked.

30. Sexual orientation and its relation to mental disorders and suicide attempts: findings from a nationally representative sample by Bolton SL, Sareen J.( published 2011)

To think about the rates of all Axis I and II mental issue and suicide endeavours in sexual introduction minorities with rates in heterosexuals utilizing a broadly illustrative example. Information utilized were from the National Epidemiologic Survey on Alcohol and Related Conditions Wave 2 ( $\mathrm{n}=34$ 653, reaction rate $=70.2 \%$ ). Cross-arrangements and multivariate logistic relapse breaks down to performed to focus contrasts in rates of mental issue and suicide endeavours by sexual introduction. All examineeare stratified by sex.

Contrasted and their hetero partners, lesbians and indiscriminate ladies showed a 3-fold improved probability of substance utilization issue, and gay and cross-sexual men showed 


\section{Homosexuality: Road to Visibility}

double the rate of uneasiness issue and schizophrenia and (or) crazy sickness, considerably in the wake of representing mental issue comorbidity. Suicide endeavours are autonomously connected with indiscriminateness, with chances 3 times higher than in heterosexuals.

Discoveries from our study underscore the way that sexual introduction minorities are helpless against poor mental wellbeing conclusions, including suicide endeavours. Clinicians need to be mindful of these particular negative mental wellbeing results when evaluating sexual introduction minorities.

\section{Female Homosexuality and Paranoid SchizophreniaA Survey of Seventy-Five Cases} and Controls by Franklin S. Klaf, M.D.(1961)

Freud's proposal that in guys neurotic maniacal side effects create as a barrier against developing oblivious gay person wishes had by and large been viewed as demonstrated without controlled checking studies. In a late clinical overview of 150 male suspicious schizophrenics and controls, Klaf and Davis3 discovered measurably noteworthy check of 3 results of Freud's hypothesis. The Freudian speculation of the genesis of jumpy side effects has been reached out to females with small supporting proof. The psychoanalytic writing on this subject has been compressed by Bychowski. An audit of the psychiatric writing uncovers a nonappearance of clinical studies and just 2 case reports. Managing homosexuality and neurotic schizophrenia in females. This paper, utilizing the same system as our past paper, endeavours a target clinical investigation of homosexuality in a gathering of 75 female neurotic schizophrenics as contrasted and 100 nonpsychotic controls.

32. Predictors of Suicide Attempts Among Gay, Lesbian, and Bisexual Youth by Scott L. Hershberger, Neil W. PiLkington, Anthony R. D'Augelli

This exploration distinguished indicators of past suicide endeavours in 194 lesbian, gay, and androgynous youth, 15 during 21 time of age, who went to social and recreational gatherings in urban group settings. In correlation to youth who made no suicide endeavours, attempters reported that they had revealed all the more totally their sexual introduction to others, had lost more companions due to their revelations, and had encountered more exploitation because of their sexual introduction. Suicide attempters had lower respect toward oneself and recognized more mental wellbeing issues. The misfortune offriends because of youth's sexual introduction, and current self-destructive ideation were among the strongest indicators of suicide endeavours. Youth who reported early consciousness of their sexual introduction, revelation to family and companions, peer dismissal, and exploitation focused around their sexual introduction may be at danger for mental wellbeing issues.

\section{The Social Environment and Suicide Attempts in Lesbian, Gay, and Bisexual Youth} Mark L. Hatzenbuehler, PhD

To figure out if the social environment encompassing lesbian, gay, and androgynous youth may help their higher rates of suicide endeavours, controlling for individual-level danger components. An aggregate of 31852 eleventh grade understudies (1413 [4.4\%] lesbian, gay, and swinger people) in Oregon finished the Oregon Healthy Teens overview in 2006-2008. They made a composite record of the social environment in 34 regions, including (1) the extent of same-sex couples, (2) the extent of enlisted Democrats, (3) the vicinity of gay-straight unions in schools, 


\section{Homosexuality: Road to Visibility}

and (4) school approaches (non-discrimination and anti-bullying) that particularly secured lesbian, gay, and androgynous understudies.

Lesbian, gay, and cross-sexual youth are essentially more inclined to endeavour suicide in the past 12 months, contrasted and heterosexuals (21.5\% vs 4.2\%). Among lesbian, gay, and swinger youth, the danger of endeavouring suicide was $20 \%$ more prominent in unsupportive situations contrasted with strong situations. A stronger social environment was essentially connected with fewer suicide endeavours, controlling for sociodemographic variables and various danger components for suicide endeavours, including depressive indications, episodic drinking, companion exploitation, and physical ill-use by a grown-up

This study records an affiliation between a destination measure of the social environment and suicide endeavours among lesbian, gay, and androgynous youth. The social environment seems to present danger for suicide endeavours well beyond individual-level danger variables. These results have essential ramifications for the advancement of arrangements and mediations to diminish sexual orientation-related differences in suicide endeavours.

34. A systematic review of mental disorder, suicide, and deliberate self-harm in lesbian, gay and bisexual people : Michael King, Joanna Semlyen, Sharon See Tai, Helen Killaspy, David Osborn,DmitriPopelyuk and Irwin Nazareth.

Lesbian, gay and swinger (LGB) individuals may be at higher danger of mental issue than hetero people. They directed a methodical survey and meta-examination of the pervasiveness of mental issue, substance abuse, suicide, self-destructive ideation and purposeful self damage in LGB individuals. They sought Medline, Embase, Psycinfo, Cinahl, the Cochrane Library Database, the They of Knowledge, the Applied Social Sciences Index and Abstracts, the International Bibliography of the Social Sciences, Sociological Abstracts, the Campbell Collaboration and light black writing databases for articles distributed January 1966 to April 2005. They likewise utilized Google and Google Scholar and reached creators where vital. They sought all terms identified with gay person, lesbian and indiscriminate individuals and all terms identified with mental issue, suicide, and intentional self-mischief. They included papers on populace based studies which contained simultaneous hetero examination bunches and legitimate meaning of sexual introduction and mental wellbeing outcomes. Of 13706 papers recognized, 476 theyre at first chose and 28 (25 studies) met incorporation criteria. Stand out study met all our four quality criteria and seven met three of these criteria. Information was concentrated on 214,344 hetero and 11,971 non hetero individuals. Meta-breaks down uncovered a twofold abundance in suicide endeavours in lesbian, gay and cross-sexual individuals [pooled danger proportion for lifetime chance 2.47 (CI 1.87, 3.28)]. The danger for gloom and uneasiness issue (over a time of 12 months or a lifetime) on meta-investigates were no less than 1.5 times higher in lesbian, gay and indiscriminate individuals (RR range 1.54-2.58) and liquor and other substance reliance in excess of 12 months was additionally 1.5 times higher (RR range 1.51-4.00). Results are comparative in both genders however meta examines uncovered that lesbian and swinger ladies are especially at danger of substance reliance (liquor 12 months: RR 4.00, CI 2.85, 5.61; medication reliance: RR 3.50, CI 1.87, 6.53; any substance utilization issue RR 3.42, CI 1.975.92), while lifetime predominance of suicide endeavour was particularly high in gay and cross- 


\section{Homosexuality: Road to Visibility}

sexual men (RR 4.28, CI 2.32, 7.88) individuals are at higher danger of mental issue, selfdestructive ideation, substance abuse, and conscious self-damage than hetero individuals.

35. Self Esteem of the Homosexuals men in kerala by Mr. Manoj M.T. Mrs. Lidiya T. Paul , Prof. A. Joseph Mrs. Jinu S. Nair

The destination of the present study was to distinguish the level of respect toward oneself of gay person men and the impact of demographic variables on respect toward oneself of them. The present study was done among 120 male gay people at Suraksha MSW Project. Purposive examining strategy was utilized for determination of examples. An extraordinarily confined poll was utilized for gathering the demographic subtle elements and the Rosenberg respect toward oneself scale was utilized for recognizing the respect toward oneself of the respondents. Measurable tests like Chi-square, One way ANOVA and Post Hoc LSD were utilized for investigation. Rosenberg respect toward oneself scale uncovered that $35.0 \%$ of the respondents have high respect toward oneself, $41.7 \%$ have medium respect toward oneself and $28 \%$ have low respect toward oneself. There wasstatistically noteworthy relationship of respect toward oneself with age, conjugal status and living status however huge relationship of respect toward oneself with different variables like habitation, instructive capability and so on discovered which are not statically critical. The aftereffects of the study show that lion's share of the respondents have medium level of respect toward oneself. The respect toward oneself of the respondents is influenced by various demographic elements including age, conjugal status and living status. Subsequently, it is reasoned that a portion of the demographic variables have an orientation on the respect toward oneself of the gay person men.

36. Surveying Indian gay men for coping skills and HIV testing patterns using the internet : KS Jethwani, SV Mishra, PS Jethwani, NS Sawant

Reviewing defenceless and detained populations is regularly difficult. Not one or the other strategies to achieve and gather touchy data in a sheltered, secure, and legitimate way can go far in tending to this unmet need. Gay person men in India live with deficient social help, minimization, and need lawful distinction. These make them less reachable by open wellbeing orgs, and make them more prone to proceed with high-chance practices, and contract human immunodeficiency infection (HIV). To comprehend adapting aptitudes and HIV testing examples of gay person men versus hetero men. A web based study utilizing a safe web stage and an anonymised poll. The short COPE Inventory was utilized to evaluate adapting styles. A sum of 124 respondents was examined. Gay person men utilized pessimistic adapting aptitudes, for example, behavioural separation and tried for HIV essentially more frequently than hetero men. Hetero respondents utilized positive adapting aptitudes all the more frequently. The most generally utilized adapting expertise by hetero men was instrumental adapting and by gay person men was acknowledgement. Generally speaking, gay person men utilized pessimistic adapting components, in the same way as behavioural withdrawal all the more frequently. The Indian family structure and social backing is likely in charge of hetero men's over-dependence on instrumental adapting, while bringing about withdrawal in gay people. The absence of lawful and social distinction of homosexuality has adversely affected lives of gay men in India. This is 
emphatically joined to unsafe mental and open wellbeing ramifications for HIV counteractive action and mental wellbeing for gay person men.

\section{Self Concept And Personality Correlates Amongst by Saha, S..}

Individuals do what they do as a result of specific singularities or qualities of their mental profile and their profiles are just precise to the degree that they empower us anticipate what they will do. It was the essential point of the present study to investigate self-idea and identity corresponds among gay people. It was conjectured that there will be high scores in negative physical and mental self-idea. It was likewise speculated that no huge relationship will be seen in self-idea and identity. Example size of this study was 30 MSM (Men who engage in sexual relations with men) inside the age gathering of 18-40. Count of the study was focused around Pearson $r$ connection technique. Results yielded clear backing for the speculations of this study. In spite of the fact that the scores demonstrated constructive association, no huge correspondence was discovered between self-idea and identity; and there theyre high scores in negative physical and mental self-idea. Nonverbal perception from conduction setting additionally backs the discoveries of the study.

\section{DISCUSSION}

The sensation of homosexuality is boundless all through history and society.

The relationship between science and sexual orientation is a subject of examination. A straightforward and particular determinant for sexual orientation has not been definitively exhibited; different studies point to distinctive, actually clashing positions, however researchers estimate that a mixture of hereditary, hormonal and social variables focus sexual introduction. Organic speculations for clarifying the reasons for sexual introduction are more popular, and natural components may include a complex transaction of hereditary elements and the early nature. These elements, which may be identified with the advancement of heterosexuals, gay person, swinger or a biogenetic introduction, incorporate qualities, pre-birth hormones, and cerebrum structure.

The utilization of twin studies gives us, in principle, with a strategy for examining the relative imperativeness of hereditary and ecological variables in the genesis of homosexuality. Bailey and Pillard's results proposed that homosexuality has a high segment of heritability. Numerous more modest investigations of the sexual introduction of twins have likewise been accounted for, which, while not broadly generalizable, frequently give bits of knowledge of contrasts in the raising environment accomplished by parts of a twin pair which can prompt dissimilar introduction in adulthood. Various scholars contemplated sexual orientation in indistinguishable twins raised separated, and discovered concordance in a male pair, yet harshness in three female sets. However, numerous methodological issues are connected with such examinations.

From the information reviewed in this report, it appears sensible to infer that male homosexuality, or, at any rate, a few "sorts" of male homosexuality, are under some level of 


\section{Homosexuality: Road to Visibility}

hereditary control, albeit different issues with this information keep more exact conclusions from being drawn. Little can be said of the birthplaces of female homosexuality.

As for the mental wellbeing issues connected with gay people, a wide assortment of the exploration proposes that gay people are no exemptions. Studies demonstrate that lesbian, gay and indiscriminate individuals show larger amounts of nervousness, gloom and self-destructive sentiments than heterosexual's men and ladies.

Numerous gay individuals have encountered:

- hostility or dismissal from family, folks and companions

- bullying and verbally abusing at school

- rejection by most standard religions

- danger of roughness in broad daylight places

- harassment from neighbours and different occupants

- casual homophobic remarks on a commonplace premise

- embarrassed reactions (and at times partiality) from experts, for example, Gps

- no insurance against segregation at work

- $\quad$ negative depiction of gay individuals in the media

Encountering these troubles can mean numerous gay and promiscuous individuals face mental wellbeing issues, including:

- difficulty tolerating their sexual introduction, prompting clashes, foreswearing, liquor illuse and seclusion

- trying to keep their sexuality a mystery through lying, imagining or heading a twofold life

- low respect toward oneself

- increased danger of fiendishness toward oneself and suicide endeavours

- damaged connections or absence of backing from families

- post-traumatic anxiety issue and melancholy from long haul impacts of harassing

Gay and lesbian youth have a place with two gatherings at high danger of suicide: youth and gay people. A greater part of suicide endeavours by gay people happen amid their childhood, and gay youth are 2 to 3 times more prone to endeavour suicide than other youngsters. They may embody up to 30 percent of finished youth suicides yearly. They regularly feel completely alone and socially withdrawn out of apprehension of unfavourable results. As an aftereffect of these weights, lesbian and gay youth are more defenceless than other youth to psychosocial issues including substance misuse, ceaseless sadness, school disappointment, early relationship clashes, being compelled to leave their families, and needing to make due all alone rashly. Each of these issues shows a danger element for self-destructive emotions and conduct among gay, lesbian, promiscuous and transsexual youth. The foundation of the issue of gay youth suicide is a general 


\section{Homosexuality: Road to Visibility}

public that oppresses and criticizes gay people while neglecting to perceive that a significant number of its childhood has a gay or lesbian introduction.

Likewise, it is clear that there are not kidding restorative outcomes to same-sex conduct. Distinguishing proof with a GLB group seems to prompt an increment in wantonness, which thus prompts a horde of Sexually Transmitted Diseases and even early passing. A humane reaction to demands for social regard and distinction of GLB connections is not to guarantee gays and lesbians that gay person connections are much the same as hetero ones, yet to call attention to the wellbeing dangers of gay sex and indiscrimination. Sanctioning same-sex connections is hindering to head honchos, representations.

\section{CONCLUSION}

Sexual orientation is not something the hetero lion's share frequently considers essentially in light of the fact that they are the standard. At the same time for those whose sexual introduction lies at either end of the chime bend of sexual conduct, considering sexual orientation is a matter of survival. Jobs, family connections, social contacts, even life itself can be endangered if one transgresses what is viewed as the standard. To love somebody of the same sex in a few social orders is to hazard their exceptionally exists; in different social orders they chance detainment alongside the loss of the solaces of family and companions, and the capability to hold work; in still different spots they chance separation both glaring and unpretentious. The yearning to carry on with an open life, the need to live with trustworthiness, and the would like to love the individual of their decision is, best case scenario an everyday battle in many social orders on the planet.

Vital to the thought of sexual orientation is the real trick of adoration; individuals are pulled in to others and are brought to those others through the natural, mental, and passionate parts of sex. This beginning physical fascination can prompt adoration. It is not exclusively whom individuals are pulled in to sexually however whom they cherish that makes sexual introduction a disputable issue. Same sex marriage is petulant and divisive not on the grounds that authorizing such unions will present budgetary and legitimate profits upon same sex accomplices, but since it accepts an affection that is outside the standard; it levels the adoration for same sex couples with the adoration for hetero couples.

Researching the progress of sexual orientation and creating a valuation for the distinctions and differences in that field will help to extend understanding of others, to change mentality and, inevitably, to bring about a significant improvement for individuals of all sexual orientation.

\section{Acknowledgement}

I would like to take this opportunity to express my profound gratitude and deep regard to my supervisor, DR ARUN KUMAR for his exemplary guidance, valuable feedback and constant encouragement throughout the duration of the project. His valuable suggestions were of immense 
help throughout my project work. His perceptive criticism kept me working to make this project in a much better way. Working under him was an extremely knowledgeable experience for me.

\section{BIBLOGRAGHY}

S.J Glass, H.J Deuel, C.A. Wright ( 2014, 9 September ) Sex Hormone Studies In Male Homosexuality, retrieved from http://press.endocrine.org/doi/abs/10.1210/endo-26-4-590

Evelyn Hooker (2014, 9 September), Being Gay Is as being straight, retrieved from http://www.apa.org/research/action/gay.aspx

Author unknown (2014, 9 September) Impact of the Decriminalization of Homosexuality in Delhi: An Empirical Study , retrieved from , http://ualr.edu/socialchange/2013/01/13/impact-of-the-decriminalizationof-homosexuality-in-delhi-an-empirical-study/

Dr. Chakraborty (2014, 9 September), Higher Risk of Mental Health Problems for Homosexuals retrieved from , http://psychcentral.com/lib/higher-risk-of-mental-health-problems-forhomosexuals/0006527

TORI DeANGELIS ( 2014, 9 September ) New data on lesbian, gay and bisexual mental health New findings overturn previous belief Retrieved from , http://www.apa.org/monitor/feb02/newdata.aspx

Paul Cameron, Ph. D. (2014, 9 September ) What Causes Homosexual Desire and Can It Be Changed?

Retrieved from , http://www.biblebelievers.com/Cameron3.html

Johnson ,Ryan.D (2014, 10 September ) Homosexuality: Nature or Nurture Retrieved from , http://allpsych.com/journal/homosexuality.html

Gregory M. Herek, Ph.D. (2014, 10 September)

Retrieved from , http://psychology.ucdavis.edu/faculty_sites/rainbow/html/bibabs.html

M Modi, J Sarna, A Sharma, YS Marfatia ( 2104 , 20 September ) , articles on homosexuality Retrieved from ,Modi M, Sarna J, Sharma A, Marfatia Y S. Abstract from current literature: Homosexuality. Indian J Sex Transm Dis 2008;29:54-6

Various authors ( 2014, 10 September ) Sage journals ( psychology )

Retrieved from,http://psp.sagepub.com/content/22/4/336.short?rss=1\&ssource=mfr

History of homosexuality (2014, 20 September), Retrieved from, http://en.wikipedia.org/wiki/History_of_homosexuality 